\title{
Valve movement response of the freshwater clam Corbicula fluminea following exposure to waterborne arsenic
}

\author{
Chung-Min Liao - Sheng-Feng Jau • \\ Chieh-Ming Lin · Li-John Jou · Chen-Wuing Liu • \\ Vivian Hsiu-Chuan Liao · Fi-John Chang
}

Accepted: 9 April 2009/Published online: 25 April 2009

(C) Springer Science+Business Media, LLC 2009

\begin{abstract}
We developed an inductance-based valvometry technique as a detection system to measure the valve daily activity in freshwater clam Corbicula fluminea in response to waterborne arsenic. Our findings reveal that $C$. fluminea experiences a valve opening in the absence of arsenic predominantly in the morning hours (03:00-08:00) with a mean daily opening/closing period of 21.32 (95\% CI: 20.58-22.05) h. Amplification of daily activity occurred in the presence of arsenic. Behavioral toxicity assays revealed arsenic detection thresholds of 0.60 (95\% CI: 0.53-0.66) $\mathrm{mg}^{-1}$ and 0.35 (95\% CI: $\left.0.30-0.40\right) \mathrm{mg} \mathrm{l}^{-1}$ for response times of 60 and $300 \mathrm{~min}$, respectively. The proposed valve daily activity model was linked with response time-specific Hill dose-response functions to predict valve opening/ closing behavior in response to arsenic. The predictive capabilities were verified satisfactory with the measurements. Our results implicate a biomonitoring system by valve daily activity in $C$. fluminea to identify safe water uses in areas with elevated arsenic.
\end{abstract}

Keywords Arsenic . Freshwater clam .

Corbicula fluminea - Valve daily activity · Toxicology .

Biomonitor

C.-M. Liao $(\bowtie) \cdot$ S.-F. Jau · C.-M. Lin · C.-W. Liu

V. H.-C. Liao - F.-J. Chang

Department of Bioenvironmental Systems Engineering,

National Taiwan University, 10617 Taipei, Taiwan, ROC

e-mail: cmliao@ntu.edu.tw

L.-J. Jou

Department of Biomechatronic Engineering, National Ilan University, 260 Ilan, Taiwan, ROC

\section{Introduction}

The use of bivalve as a surrogate species in metal toxicity testing has supported the hypotheses that bivalve is a viable indicator of impairment in aquatic ecosystems (Tran et al. 2003; Liao et al. 2005; Ait Fdil et al. 2006; Jou and Liao 2006). Newton and Cope (2007) pointed out that valve activity in freshwater bivalves has promise as a biological response to contaminants because it is relatively easy and inexpensive to monitor, mirroring responses at environmentally realistic concentrations. Cherry and Soucek (2007) have intensively reviewed the practical uses of freshwater clam Corbicula fluminea as an in situ monitoring test organism, underscoring the increasing importance of integrating in situ bioassays using field-caged bivalves with traditional measures of ecological integrity.

Dell'Omo (2002) indicated that behavioral parameters reflect behavioral toxicity, suggesting that behavioral responses might be faster and more sensitive toxicity parameters than mortality. Gerhardt et al. (2005) pointed out that behavioral responses could be used in biological early warning systems (BEWS) for automated biomonitoring incorporated with exposure time and mortality considerations into the alarm setting mechanisms. Gerhardt et al. $(2005,2006)$ further indicated that behavioral parameters could add another dimension for providing more sensitivity and ecological relevance to standard toxicity testing, suggesting that behavioral parameters are particularly suitable used in online biomonitors. Ortmann and Grieshaber (2003) demonstrated that C. fluminea present daily activities in valve movement in the summer time. Gerhardt et al. (2005) suggested that it is urgently needed to define daily activity changes as a new behavioral test parameter to provide a candidate factor in BEWS for biomonitoring the emerging contaminants. 
Ingested inorganic arsenic that is known to have adverse human health effects are thought to contribute to some complex diseases such as skin lesions, diabetes, cardiovascular disease, and cancers of several organs (lung, bladder, kidney) in arseniasis-endemic areas in southwestern and northeastern Taiwan (Chen et al. 2005; Lamm et al. 2006). Lin et al. (2001, 2005), Liao et al. (2003), Huang et al. (2003), and Liu et al. $(2006,2007)$ have conducted a long-term investigation during 1998-2007 in arseniasis-endemic areas of Taiwan and indicated that arsenic was detected in many farm fish and shellfish ponds. Taken together, they reported that arsenic concentrations in aquaculture waters ranged from 40 to $900 \mu \mathrm{g}^{-1}$, whereas, arsenic levels in fish (tilapia Oreochomis mossanbicus, milkfish Chanos chanos, and large-scale mullet Liza macrolepis) and shellfish (hard clam Meretrix lusoria and oyster Crassostrea gigas) ranged between 1-350 and 4-23 $\mu \mathrm{g} \mathrm{g}^{-1}$ dry wt, respectively.

The purpose of this paper was to characterize quantitatively the behavior response of valve opening/closing activity in freshwater clam $C$. fluminea exposed to waterborne arsenic. We developed an inductance-based valvometry technique as a detection system to measure the valve daily activity in response to waterborne arsenic. A behavioral toxicity assays was also conducted to estimate arsenic detection thresholds by valve daily activity. This study can provide a primary framework to link the proposed daily activity dynamics with behavioral toxicity assay-derived dose-response model to design a dynamic detection system that can be deployed in the elevated arsenic areas to identify the safe sources for water uses.

\section{Materials and methods}

\section{Acclimation}

We collected 320 C. fluminea from clam farms situated at Hualien of eastern Taiwan with a mean shell length of $28.4 \pm 1.8 \mathrm{~mm}$ (mean $\pm \mathrm{SD}$ ) and a mean body weight of $6.32 \pm 0.71 \mathrm{~g}$ wet wt. Before any experiments, tested clams were acclimated in the synthetic water obtained from Hualien clam farms under the laboratory conditions for at least 3 weeks to rescue clams behavior such as burrowing and siphon retraction. The water was air-equilibrated by bubbling, with an artificial photoperiod (day: 10:00-22:00 and night: 22:00-10:00). About 80 clams were hatched per tank (indoor rectangular fiberglass aquaria measuring $60 \times 36 \times 31 \mathrm{~cm}^{3}$ ), containing 501 of water in a flowthrough circulation system. The tested clams were continuously fed during the acclimation period with the cultured algae Platymonas sp. using a pump.

Acclimated water conditions were as follows. Temperature: $22.14 \pm 1.11^{\circ} \mathrm{C}, \quad \mathrm{pH}: \quad 8.12 \pm 0.06, \quad$ DO: $8.6 \pm$
$0.16 \mathrm{mg} \mathrm{l}^{-1}$, salinity: 0.10 , and turbidity: $23.08 \pm 0.04$. Water ionic compositions were $\mathrm{Ca}^{2+}: 24.8 \mathrm{mg} / \mathrm{l}, \mathrm{Mg}^{2+}$ : $1.0 \mathrm{mg} \mathrm{l}^{-1}, \mathrm{Na}^{+}: 4.9 \mathrm{mg} \mathrm{l}^{-1}, \mathrm{~K}^{+}: 2.7 \mathrm{mg} / \mathrm{l}, \mathrm{H}^{+}: 7.21$, $\mathrm{NH}_{4}^{+}: 0.26 \mathrm{mg} \mathrm{l}^{-1}, \mathrm{Cl}^{-}: 7.6 \mathrm{mg} \mathrm{l}^{-1}, \mathrm{NO}_{2}^{-}: 0.047 \mathrm{mg} \mathrm{l}^{-1}$, and $\mathrm{NO}_{3}^{-}: 0.318 \mathrm{mg} \mathrm{l}^{-1}$. No mortality was observed during acclimation. Ionic components in water samples were measured followed by standard methods (APHA 2005).

\section{Valve movement experiment}

The measuring method used in this study is inspired by the ideas described by Tran et al. (2003) and the website http://www.domino.u-bordeaux.fr/molluscan_eye. Exploiting this published method allowed us to create a new method that is still handles valve behavior measurements. We continuously recorded the valve movements in C. fluminea from April 3-17, 2007 using our own developed valvometry measuring systems. In this study, a measuring system based on the inductance valvometry technique using a pair of light-weighted electrical coils was developed to detect the valve movement of unconstrained $C$. fluminea in low-stress conditions. The valvometry technique mainly applied the electromagnetic inducing action and principle to measure the distance between two different electrical coils as the sensing theory for determining the magnitudes of shell gape (Fig. 1). The developed valvometry system (Fig. 1) employing a graphic control program language (LabVIEW8.0) in a personal computer (PC) associated with a data acquisition interface card (NI DAQPad-6259) was used to dynamically and real-time observe the valve closing/opening activities in a group of clams.

The measuring technique of the electromagnetic inducing action in alternating current (AC) circuit was applied to the inductance valvometer using an alternating potential difference produced by a function generator at a frequency of $4 \mathrm{kHz}$ with a constant potential of $2,000 \mathrm{mV}$ connected to one of the two electrical coils. Another electrical coil attached on clam valve was inducted to accordingly produce various signal voltages in accordance to the openness of valve opening activities. Our developed inductance valvometry measuring system was based on a high-frequency (HF) electromagnetic induction system that can measure the varying distance between two electrical coils glued onto each valve. One coil was used as a transmitter of a magnetic field generated by an oscillating sinusoidal current of $4 \mathrm{kHz}$. Another coil can intercept part of this magnetic field and induce an AC sinusoidal voltage. Thus, the magnitude of the induced signal voltage inversely proportioned to the distance between two inductances glued on the valves was transformed to indicate the status of shell position of each clam.

In this study, three different monitoring responses with respect to behavioral activities in $C$. fluminea can be 
Fig. 1 A simplified diagram of our laboratory experimental setup and implementation for observing and measuring valve opening/closing in C. fluminea based on the present developed inductance-based valvometry measurement technique. See main text for details

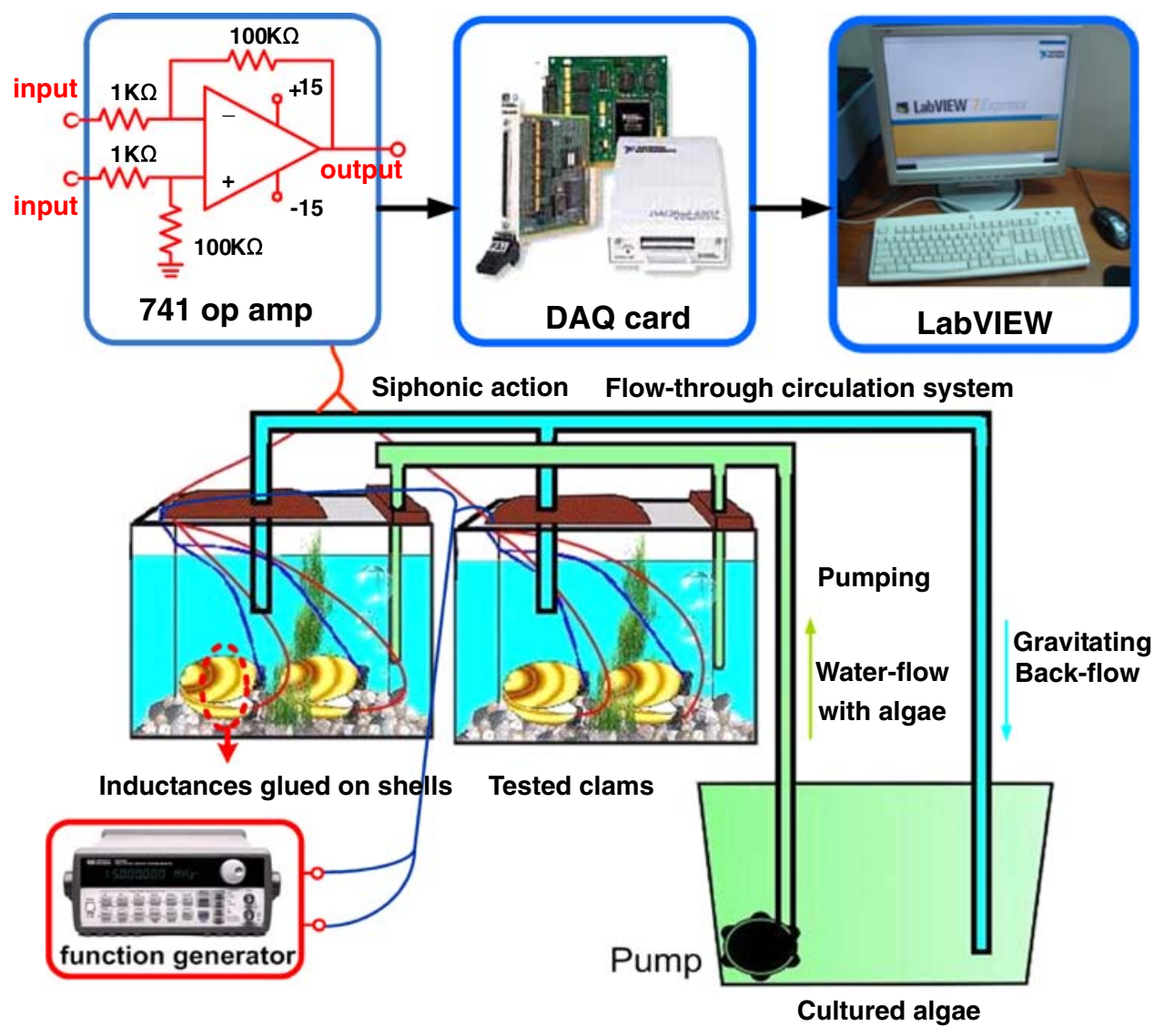

appropriately selected as representing changes in the valve movement in response to arsenic: (1) the percentage of valve closing/opening in a group of clams, i.e., the proportion of a given number of clams showing closing/ opening state at the same time to the total number of clams, (2) the average magnitude of the shell gape in each clams, and (3) the average daily duration of valve opening/closing activities in a group of clams. With the present developed equipment, the overall valve movements were recorded by connecting the processed voltage signals to a PC. By setting a constant sampling time interval, the acquired voltage signal from each single specimen was recorded using a PC linked with our developed monitor-specific LabVIEW software to obtain continuous observations of individual magnitudes of shell gape (\%). The mean magnitudes of shell gape (\%) in C. fluminea at hourly intervals throughout the day can be precisely calculated and analyzed through the built-in and menu-driven LabVIEW computer program. Thus, our developed bivalve-monitor can determine and record the trace at any relative valve positions of unconfined $C$. fluminea.

\section{Behavioral toxicity assays}

Valve movement behavioral toxicity assays were performed from April to May 2007. About 16 clams of a specific size class (i.e., mean shell length $=28.4 \mathrm{~mm}$ and mean body weight $=6.32 \mathrm{~g}$ wet $\mathrm{wt}$ ) were randomly selected and transferred into each test aquarium $\left(45 \times 21 \times 26 \mathrm{~cm}^{3}\right)$ containing 201 of water to obtain the does-response profiles with various exposure arsenic concentrations under different integrated response times. The sodium arsenite $\left(\mathrm{NaAsO}_{2}\right)$ stock solution was prepared with deionized water. The behavioral endpoint is valve closing response. $C$. fluminea were exposed under various arsenic concentrations of $0.3,0.5,1,5$, and $10 \mathrm{mg}^{-1}$ with a mean $\mathrm{pH}$ of 8.0 and a mean temperature of $22^{\circ} \mathrm{C}$. No mortality was observed during the behavioral assays. A Perkin-Elmer Model 5100PC atomic absorption spectrometer (PerkinsElmer, Shelton, CT, USA) equipped with an HGA-300 graphite furnace atomizer was used to measure total arsenic. The levels of detection were $0.62 \mu \mathrm{g}$ arsenic per liter.

\section{Data analysis}

The does-response profile was constructed by fitting the three-parameter Hill equation model to the observed data from proposed behavioral assays of response time-specific valve closing response as a function of arsenic concentration;

$R\left(C_{\mathrm{w}}\right)=\frac{R_{\max } \times C_{\mathrm{w}}^{n}}{\mathrm{EC}^{n} 0^{n}+C_{\mathrm{w}}^{n}}$, 
where $R$ is the measured valve closing response (\%), EC50 is the behavioral effect concentration of arsenic yielding half of maximal response of $R_{\max }\left(\mathrm{mg}^{-1}\right), C_{\mathrm{w}}$ is the arsenic concentration in water $\left(\mathrm{mg} \mathrm{l}^{-1}\right)$, and the exponent $n$ is a fitted Hill coefficient which is a measure of cooperativity. The effect concentration EC50 values were estimated at different response times of 10, 15, 30, 60, 120, and $300 \mathrm{~min}$. The Hill mathematical model was used because it allows for comparison of cooperativity among different response time periods.

We employed the function of nonlinear regression of the TableCurve 2D (Version 5, AISN Software Inc., Mapleton, OR, USA) package to perform all curve fittings. Statistical significance was judged by $p$ values less than 0.05. A Monte Carlo technique was performed to generate 2.5- and 97.5-percentiles as the 95\% confidence interval (CI) for all fitted models. We employed Crystal Ball $^{\circledR}$ software (Version 2000.2, Decisionerring, Inc., Denver, Colorado, USA) to implement the Monte Carlo simulation.

\section{Results}

Valve daily activity

Figure 2a shows a 14-day continuous recording of individual valve opening/closing activity of shell gape under the status of spontaneous behavior, revealing the variation of daily valve activity of the $16 C$. fluminea. For each trace demonstrated in Fig. 2a, C. fluminea at valve closing was represented by the baseline level. Figure $2 b$ demonstrates
Fig. 2 Valve daily activity in C. fluminea. a A continuous recording of individual valve opening/closing status from April 3, 2007-April 17, 2007 for 14 days. b The fitted daily activity expressed as a sine function based on $\%$ valve closing in a group of 16 clams. c The fitted daily activity model based on the magnitude of shall gape. d Probability distribution of valve opening time period. Error bars denote the standard deviation from the mean
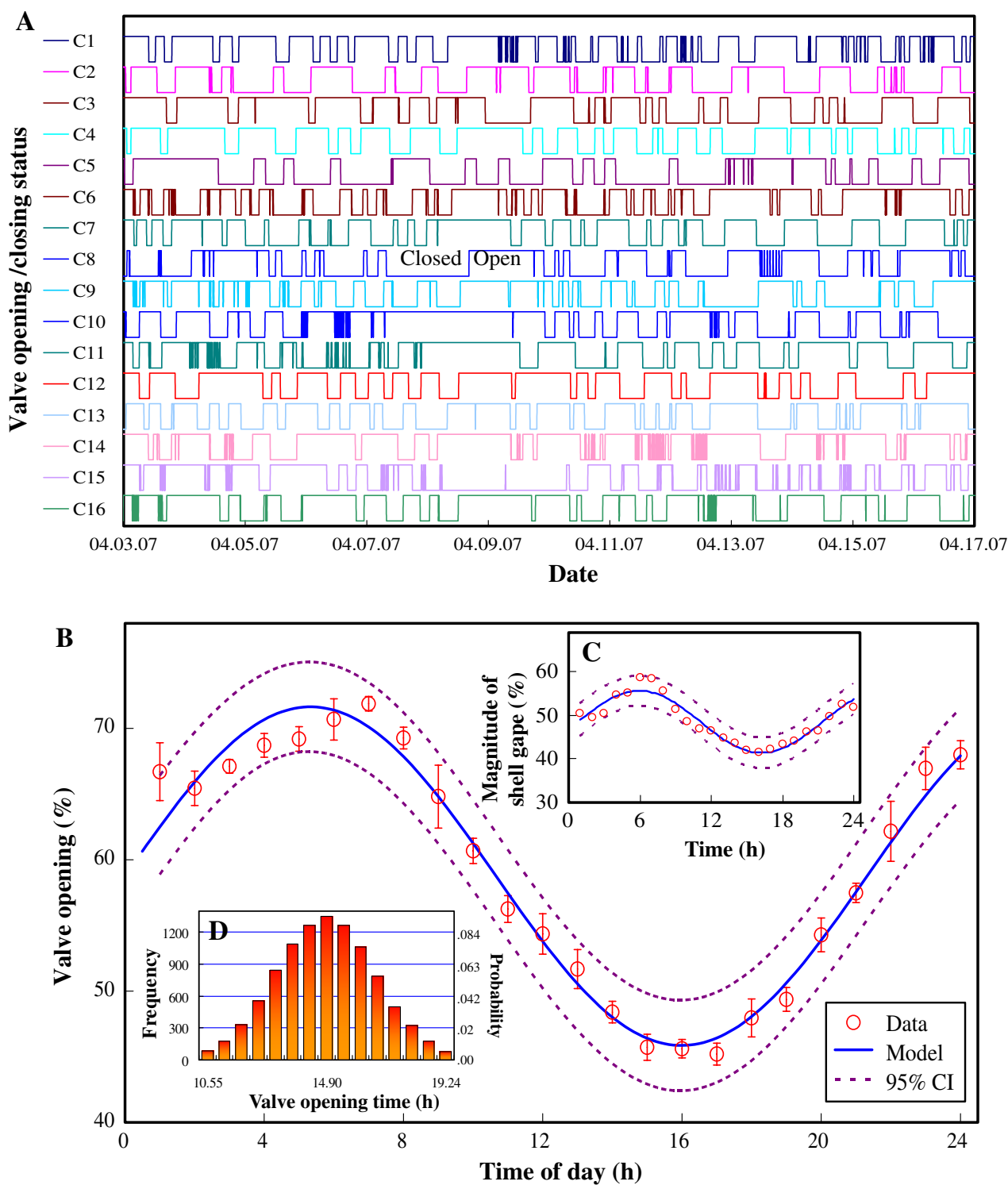
the mean probability of valve opening of the 16 clams at hourly intervals during the observed duration. Each value shown in Fig. $2 b$ is the mean of a total of 192 readings taken every 5 min during each hour for each $C$. fluminea for a 14-day observation period $(14 \times 12$ readings per hour per clam). Our results reveal that valve opening behavior of these $16 C$. fluminea follows an impressive daily activity (Fig. 2b). The daily activity of valve opening in $C$. fluminea in the absence of arsenic is best described $\left(N=16, r^{2}=0.98\right)$ by a 4-parameter sine function as

$\psi(t)=B \times A \times \sin \left(\frac{2 \pi(t+\varphi)}{\tau}\right)$,

with a base line $B=0.59$, an amplitude $A=0.13$, a phase $\varphi=0.034 \mathrm{~h}$, and a daily period $\tau=21.32 \mathrm{~h}(95 \% \mathrm{CI}$ : 20.58-22.05 h). Moreover, we also used the valve daily activity model to fit our data based on magnitude of shall gape, resulting in $\tau=20.57 \mathrm{~h}$ with $\varphi=19.78 \mathrm{~h}$ $\left(r^{2}=0.92\right.$; Fig 2c).

The results also indicate that valve opening response is predominantly in the morning hours of 03:00-08:00 h. Here we used a Monte Carlo simulation technique to obtain the probabilistic distribution of valve daily opening time of C. flumena. We divided 15 bins in the 10,000 iterations Monte Carlo simulation for each interval time based on the average percentage of clam daily opening time in 14 days (Fig. 2d): $\Delta t_{i}=(19.24-10.55) / 15=0.579 \mathrm{~h}$. We used the occurring probability of opening time expressed as $P\left(t_{i}\right)=$ $n_{t_{i}} / N$ with $N=\sum_{i=1}^{15} n_{t_{i}}, \quad i=1-15$ to estimate accordingly the number of $C$. fluminea under the various opening times where $P\left(t_{i}\right)$ is the occurring probability of opening time $t_{i}, N$ is the total number of bivalves, and $n_{t_{i}}$ is the number under the condition of opening time $t_{i}$. The results shows that the estimate was calculated to be $61.97 \pm 7.69 \%$ (mean $\pm \mathrm{SD}$ ) that can be converted into a 24 -h based value expressed as a best fitted normal distribution with a mean $14.87 \mathrm{~h}$ and a standard deviation $1.85 \mathrm{~h}$ (Fig. 2d). Thus the mean daily valve opening time is nearly $15 \mathrm{~h}$.

\section{Dose-response}

Figure 3 shows the fitted Hill model based arsenic concentration-valve closing response relationships varied with different response times of 10, 15, 30, 60, 120, and $300 \mathrm{~min}$. The Hill model and a 10,000 Monte Carlo simulation provided an adequate fit for the data ( $\chi^{2}$ goodness-of-fit, $p>0.5)$ with high $r^{2}$ values $(0.991-0.997, p<0.05$; Fig 3$)$. The fitted Hill coefficients $(n)$ ranged from 1.63 to 3.67, indicating positive cooperativity. Based on our fitted doesresponse model (Fig. 3), the EC50 values are estimated to be $4.65,3.48,1.38,0.60,0.38$ and $0.35 \mathrm{mg} / \mathrm{l}$ for valve response times of 10, 15, 30, 60, 120, and $300 \mathrm{~min}$, respectively. Fig 3 also reveals that low concentrations of arsenic cause a significant change in the valve position, suggesting that valve position is suitable for a biologically sensitive endpoint. The estimated effective time caused $50 \%$ response (ET50) values decrease notably from $80.2 \mathrm{~min}$ at $0.3 \mathrm{mg} \mathrm{l}^{-1}$ arsenic to $16.2 \mathrm{~min}$ at $10 \mathrm{mg} \mathrm{l}^{-1}$ arsenic.

Here we used a Hill model-based does-response-time surface function to describe the response

$R\left(t_{\mathrm{R}}, C_{\mathrm{w}}\right)=\frac{R_{\max } \times C_{\mathrm{W}}^{n\left(t_{\mathrm{R}}\right)}}{\left[\mathrm{EC} 50\left(t_{\mathrm{R}}\right)\right]^{n\left(t_{\mathrm{R}}\right)}+C_{\mathrm{w}}^{n\left(t_{\mathrm{R}}\right)}}$

where $t_{\mathrm{R}}$ is the integrated response time (min) and EC50 $\left(t_{\mathrm{R}}\right)$ and $n\left(t_{\mathrm{R}}\right)$ are response time-dependent EC50 and Hill coefficient, respectively. A non-linear exponential model of $\operatorname{EC} 50\left(t_{\mathrm{R}}\right)=0.39+8.62 \exp \left(-t_{\mathrm{R}} / a\right)$ is best fitted the $\operatorname{EC} 50\left(t_{\mathrm{R}}\right)-t_{\mathrm{R}}$ relationships with $a=14.34(95 \% \mathrm{CI}$ : $\left.11.83-16.85 ; r^{2}=0.99\right)$. On the other hand, $n\left(t_{\mathrm{R}}\right)=$ $1.65+2.50 \exp \left(-t_{\mathrm{R}} / a\right)$ with $a=18.8$ (95\% CI: 13.9 23.8) also give a best-fitted expression for Hill coefficient $\left(r^{2}=0.99\right)$. We also normalize relationships between the daily valve closing time and arsenic concentration followed the Hill model $\left(r^{2}=0.99\right)$, indicating that EC50 is estimated to be $0.55(95 \% \mathrm{CI}: 0.42-0.68) \mathrm{mg} \mathrm{l}^{-1}$ with a $R_{\max }=0.74$ and $n=2.4$.

Valve daily activity in response to arsenic

To investigate the dynamics of valve daily activity in response to arsenic, we conducted an experiment by adding different exposure arsenic concentrations of $0.3,0.5,1.0$, 5.0 , and $10 \mathrm{mg} \mathrm{l}^{-1}$ at the morning hour of $03: 00 \mathrm{~h}$ to continuously observe the daily activity changes in valve opening responses. We collected the valve response data at the morning valve opening hours between 03:00 and 08:00 h. Here we link the predicted valve daily activity function in clam and Hill model based time- and concentration-specific valve closing response to predict the valve daily activity in response to arsenic,

$$
\begin{aligned}
\psi\left(t, C_{\mathrm{w}}\right) & =\psi(t, 0)-\psi(t, 0) \times R\left(t_{\mathrm{R}}, C_{\mathrm{w}}\right) \\
& =\psi(t, 0) \times\left[1-R\left(t_{\mathrm{R}}, C_{\mathrm{w}}\right)\right]
\end{aligned}
$$

where $\psi\left(t, C_{\mathrm{w}}\right)$ is the daily activity function of valve opening at time $t$ in response to arsenic, $\psi(t, 0)=0.59+$ $0.13 \times \sin (2 \pi(t+0.034) / 21.32)$ is the proposed daily activity model of valve opening at time $t$ in the absence of arsenic (Eq. 2, Fig 2b), and $R\left(t_{\mathrm{R}}, C_{\mathrm{w}}\right)$ is the response time $\left(t_{\mathrm{R}}\right)$-dependent Hill model based valve closing response in response to arsenic (Eq. 3).

The simulation results (Fig. 4a) indicate that in the valve opening hours from 03:00 to 08:00 h the predicted daily activity changes in valve opening in response to different arsenic exposure concentrations ranging from 0.3 to $10 \mathrm{mg}^{-1}$ are notably agreed satisfactory with the 
Fig. 3 Hill based doesresponse models fit to measured data $(\square)$ varied by different integrated response times of a 10 , b 15 , c 30, d 60, e 120, and f $300 \mathrm{~min}$, respectively, showing the relationship between arsenic exposure concentration and \% valve closing response in $C$. fluminea (median with $95 \% \mathrm{CI}$ ). Error bars denote the standard deviation from the mean
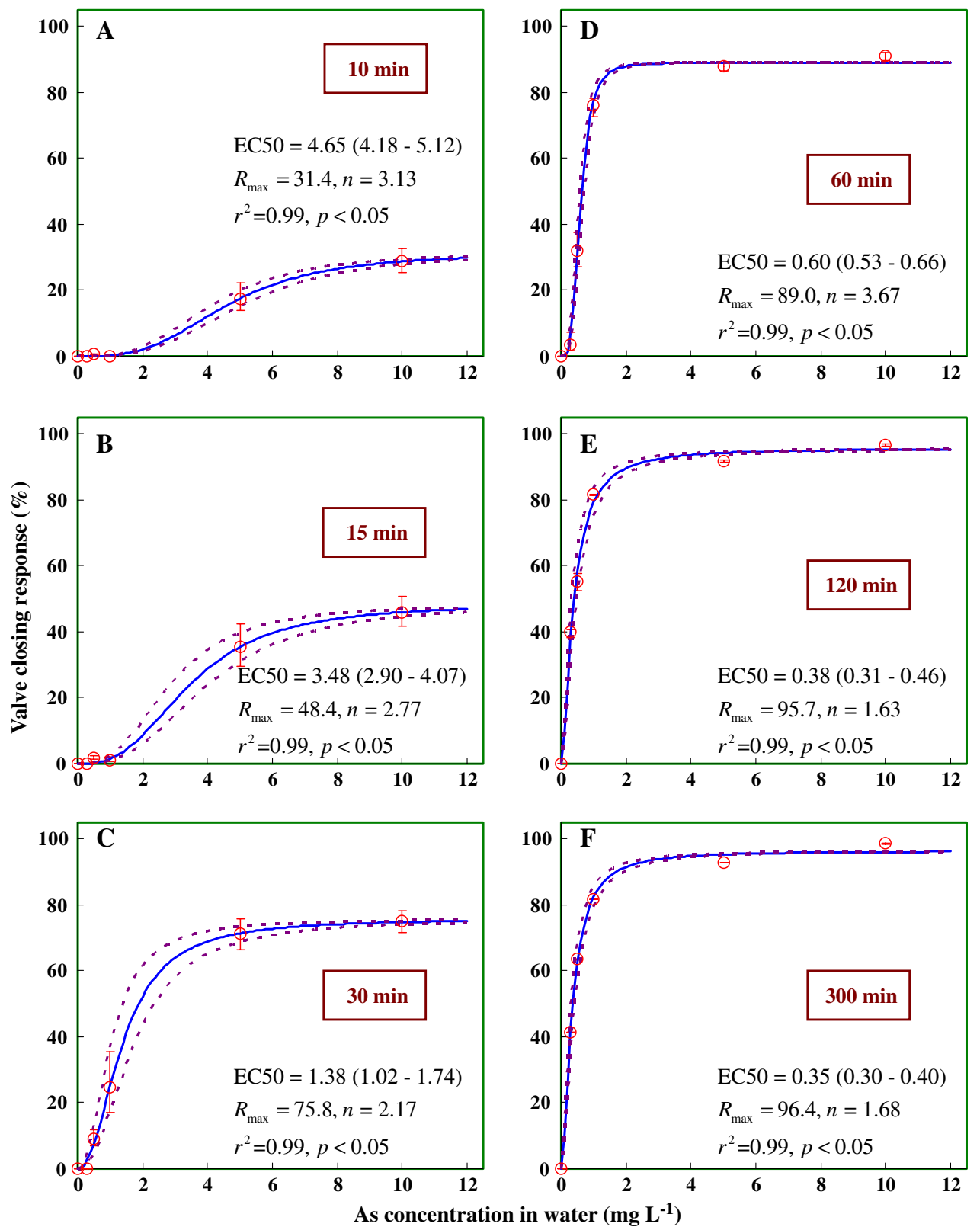

observations justified by the root mean squared errors (RMSE) ranging from 4 to $10 \%$ (Fig. $4 \mathrm{~b}$ ). Our results also demonstrate that waterborne arsenic concentrations of $>0.3 \mathrm{mg} \mathrm{l}^{-1}$ have dramatically effects on valve opening activities (Fig. 4c-h).

\section{Discussion}

Valve daily activity dynamics

In this work our efforts were to characterize the valve daily activitys in $C$. fluminea in response to waterborne arsenic. We used the present developed inductance-based valvometry technique to observe and measure the valve movement, revealing a daily activity with a mean daily period of $21.32 \mathrm{~h}$ and a mean daily valve opening time of $14.87 \mathrm{~h}$ predominantly in the morning hours. We used Hill model to construct response time-specific does-response relationships to estimate response time-specific EC50 values. Better measurements are needed to ultimately build models with predictive capabilities. We therefore link proposed valve daily activity model and Hill model to predict valve daily activity dynamics in response to arsenic.

To show the endogenous nature of daily activity in C. fluminea, estimated daily period $(\tau=21.32 \mathrm{~h})$ in the daily activity model shown in Eq. 2 was tested against a 

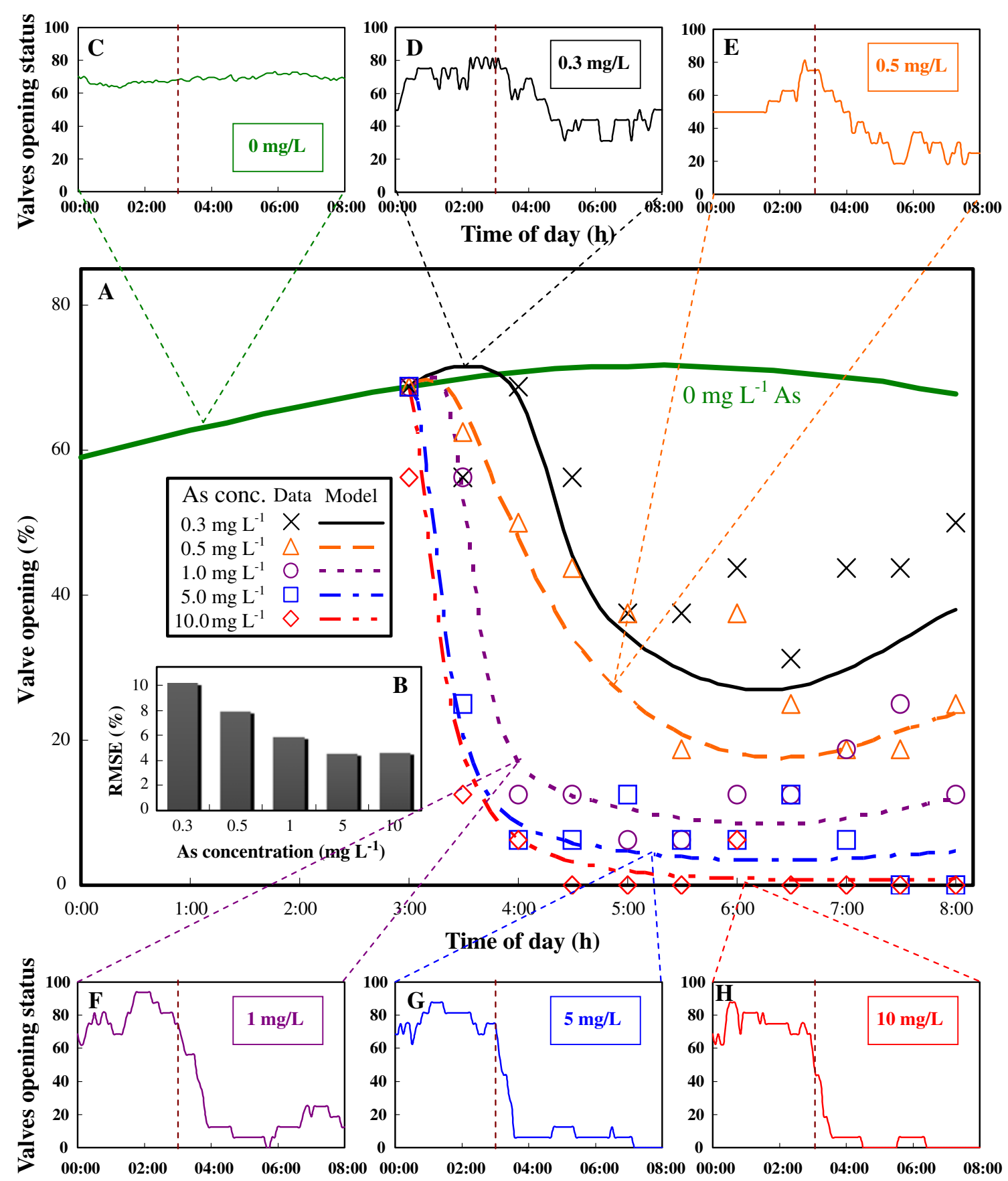

Time of day (h)

Fig. 4 Predictions of valve daily activitys in $C$. fluminea in response to arsenic. a Simulation results of valve daily activity changes in response to waterborne arsenic concentrations ranging from 0.3 to $10 \mathrm{mg} \mathrm{l}^{-1}$. b Model verification justified by root mean squared errors

similar model where $\tau$ was fixed to the exogenous daily activity of $24 \mathrm{~h}$. Estimated $\tau$ model produced significantly better fits $\left(r^{2}=0.98\right)$ than that of fixed $\tau$ model $\left(r^{2}=0.93\right)$, indicating valve daily activity in $C$. fluminea with daily periods ranging from 20.58 to $22.05 \mathrm{~h}$. We used our derived valve daily activity model to fit the published
(RMSE) varied by different arsenic concentrations. $\mathbf{c}-\mathbf{h}$ Measured average valve opening status changes $(n=16)$ exposed to waterborne arsenic concentrations ranging from 0 to $10 \mathrm{mg}^{-1}$

data related to valve closure behavior. The results show that the estimated daily periods $\tau=23.85 \mathrm{~h}$ with $\varphi=12.76 \mathrm{~h}\left(N=8, r^{2}=0.95\right)$ for freshwater mussel (Dreissena polymorpha) based on \% average valve position data (Sluyts et al. 1996) and $\tau=27.12 \mathrm{~h}$ with $\varphi=17.4 \mathrm{~h}$ $\left(N=8, r^{2}=0.99\right)$ for $C$. fluminea based on $\%$ magnitude 
of shell gape data (Ortmann and Grieshaber 2003), revealing similar daily activity.

Our estimated magnitude of shell gape based $\tau=20.57 \mathrm{~h}$ that is shorter than that of Ortmann and Grieshaber (2003) of $27.12 \mathrm{~h}$. The differences plausibly stem largely from different experimental setup, regiondependent mechanisms involved in the control of endogenous daily activity in $C$. fluminea, and other environmental factors. These data may provide a role for free-running daily periods in modulating bivalve daily homeostasis and a biological mechanism whereby this can occur.

\section{Dynamic detection system}

We compared our estimated response time-specific EC50 values with other metals on $\%$ valve closing responses (Table 1), indicating that mercury and copper have the similar ranged values of EC50, whereas, clams have the relative higher EC50 values in response to cadmium and arsenic than those of mercury and copper with one and two order of magnitude, respectively. Table 1 also reveals that in $C$. fluminea, under the range $(95 \% \mathrm{CI})$ of $2.0-5.4 \mu \mathrm{g} \mathrm{l}^{-1}$ for mercury, 2.3-8.8 $\mu \mathrm{g} \mathrm{l}^{-1}$ for copper, $16 \mu \mathrm{g} \mathrm{l^{-1 }}$ for

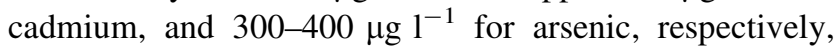
require at least $5 \mathrm{~h}$ to be detected.

Here our study also gives the response time-dependent EC10 and EC5 models. The results show that the best fitted $\mathrm{EC} 10\left(t_{\mathrm{R}}\right)=0.18+10.43 \exp \left(-t_{\mathrm{R}} / a\right) \quad\left(r^{2}=0.99\right) \quad$ and $\mathrm{EC} 5\left(t_{\mathrm{R}}\right)=0.13+8.03 \quad \exp \left(-t_{\mathrm{R}} / a\right) \quad\left(r^{2}=0.99\right) \quad$ with $a=9.06$ (95\% CI: 6.18-11.93) and 8.85 (95\% CI: 5.5312.18), respectively. Therefore, detection thresholds of $130 \mu \mathrm{g} / \mathrm{l}$ for $300 \mathrm{~min}$ and $420 \mu \mathrm{g} \mathrm{l}^{-1}$ for $30 \mathrm{~min}$ are allowed by using EC5 $\left(t_{\mathrm{R}}\right)$ model in the situation considered. Arsenic was detected in many farm fish and shellfish ponds in arseniasis-endemic areas ranging from 40 to $900 \mu \mathrm{g}^{-1}$ (Lin et al. 2001, 2005; Liao et al. 2003; Huang et al. 2003; Liu et al. 2006, 2007). The valve daily activity in $C$. fluminea can therefore be used as a suitable biomonitoring system in aquaculture water quality problems that are characterized by complex and pollutant precursor concentrations.

\section{Implications}

Traditional techniques of assessing aquatic organism exposure to chemical contaminants involve measuring the potentially external toxic agent or exposure via water samples or internal target organ specimens of study organisms. These assays, however, are not intended to provide information on the extent of the environmental exposure, the biological responses of organisms, or more importantly, the temporal relation between exposure and biological response. The organism and dynamic features of the exposure and its impact on fundamental biological processes are not easily to capture by existing assessment techniques. Recent advances in environmental and biological monitors suggest that the technologies are at hand and can be readily engineered not only to provide robust measures of chemical hazards at the point of contact but also to characterize the physiological/behavioral responses. Sensor technologies embrace exceptional promise for providing crucial information for real-time data collection and simultaneous measurement of multiple agents within a single device.

For any type of toxicity detection mechanism, false alarm is one important issue that needs to be especially addressed. In our situation, EC5, the concentration at which $5 \%$ of $C$. fluminea reactions are observed, could increase the risk of a false alarm. On the other hand, the occurrence of false alarms may be provoked by equipment malfunctions or changes in water quality conditions. For instance, when precipitation causes simultaneous changes in temperature, dissolved oxygen, $\mathrm{pH}$, whereas, the suspended particulates in surface water containing toxic chemicals are

Table 1 A comparison of metal- and response time-specific EC50 values (mean with 95\% CI) for C. fluminea based on \% valve closing response

\begin{tabular}{|c|c|c|c|c|}
\hline & \multicolumn{4}{|c|}{ Integrated response time $(\mathrm{min})$} \\
\hline & 30 & 60 & 120 & 300 \\
\hline Metal & EC50 value $\left(\mu \mathrm{g} \mathrm{l}^{-1}\right)$ & & & \\
\hline Mercury $^{\mathrm{a}}$ & $20.3(11.9-32.1)$ & $8.9(5.1-15.8)$ & $5.8(3.4-10.3)$ & $3.1(2.0-5.4)$ \\
\hline Copper $^{\mathrm{b}}$ & $21.4(8.9-34.2)$ & $10.9(5.5-21.2)$ & $8.1(4.2-16.0)$ & $4.2(2.3-8.8)$ \\
\hline Cadmium $^{\mathrm{c}}$ & 155 & 45 & 35 & 16 \\
\hline Arsenic $^{\mathrm{d}}$ & $1,380(1,020-1,740)$ & $600(530-660)$ & $380(310-460)$ & $350(300-400)$ \\
\hline
\end{tabular}


washed into the aquatic environment. In this case, careful evaluation of response patterns is quite critical to identify the cause of alarm, and it is essential and auxiliary to monitor the common water quality parameters such as temperature, dissolved oxygen, $\mathrm{pH}$ and conductivity for reducing the occurrence probability of false alarms (van der Schalie et al. 2001) More parameters could be added to improve the performance further.

Looking forward, we envisaged that to design a dynamic BEWS based on optimal quantification of valve movement in $C$. fluminea might eventually involve a variety of dose response-prediction approaches. However, by linking Hill model-based dose-response relationships and valve activity model has an important theoretical advantage. It can potentially take account of both physiological and environmental factors affecting valve behavior in response to arsenic. Our proposed framework would potentially relate to predicting the dynamic behavior of valve daily activity in response to arsenic and the likelihood of sensitivity threshold estimates based on EC5 or EC10 response functions. We proposed that similar methodology could be applied to predicting potential population-level long-term responses to broader challenges on other bivalves in response to other waterborne contaminants to identify safe water sources.

Our study of bivalve behavior ecotoxicology has limitations that should be addressed by future research. To our knowledge, our study is the first to quantitatively address the effects of waterborne arsenic on valve circadian rhythms characterization in Asiatic clam C. fluminea. The present study was mainly based on our own developed inductance-based valvometry measurement technique linked with reliable statistical modeling approaches. The implication of this study is to design a dynamic biomonitoring system for potential in situ detection of waterborne arsenic concentrations by a valve daily activity in C. fluminea to identify the safe sources in the areas with elevated arsenic for water uses. The valve daily activitybased biomonitoring system may integrate with the potential in situ arsenic remediation strategies to assist in arsenic water quality monitoring and management.

Acknowledgments The authors acknowledge the National Science Council of Republic of China for financial support under the Grant NSC 95-2313-B-002-052-MY3. We also thank Biosystems Modeling and Control Lab members for assistance with collection of field samples and assays. This work was inspired by the original paper appeared in Environmental Toxicology and Chemistry 22: 914-920 (2003) by Dr. Tran and coworkers.

\section{References}

Ait Fdil M, Mouabad A, Outzourhit A, Benhra A, Maarouf A, Pihan JC (2006) Valve movement response of the mussel Mytilus galloprovincialis to metals $(\mathrm{Cu}, \mathrm{Hg}, \mathrm{Cd}$ and $\mathrm{Zn})$ and phosphate effluents from Moroccan Atlantic coast. Ecotoxicol 15:477-486. doi:10.1007/s10646-006-0083-3

APHA (2005) Standard methods for the examination of water and wastewater, 20th edn. American Public Health Association, Washington

Chen CJ, Hsu LI, Wang CH, Shih WL, Hsu YH, Tseng MP et al (2005) Biomarkers of exposure, effect, and susceptibility of arsenic-induced health hazards in Taiwan. Toxicol Appl Pharmacol 206:198-206. doi:10.1016/j.taap.2004.10.023

Cherry DS, Soucek DJ (2007) Case study: comparison of Asian clam (Corbicula fluminea) in situ testing to several nontarget test organism response to biocidal dosing at a nuclear power plant. In: Farris JL, van Hassel JH (eds) Freshwater bivalve ecotoxicology. Roca Raton, London, NY, pp 285-310

Dell'Omo M (2002) Behavioural ecotoxicology. Chichester, New York, p 463

Gerhardt A, De Bisthoven LJ, Soares AMV (2005) Evidence for the stepwise stress model: Gambusia holbrooki and Daphnia magna under acid mine drainage and acidified reference water stress. Environ Sci Technol 39:4150-4158. doi:10.1021/es048589f

Gerhardt A, de Bisthoven LJ, Schmidt S (2006) Automated recording of vertical negative phototactic behaviour in Daphnia magna Straus (Crustacea). Hydrobiologia 559:433-441. doi:10.1007/ s10750-005-1259-1

Huang YK, Lin KH, Chen HW, Chang CC, Liu CW, Yang MH et al (2003) Arsenic species contents at aquaculture farm and in farmed mouthbreeder (Oreochromis mossambicus) in blackfoot disease hyperendemic areas. Food Chem Toxicol 41:1491-1500. doi:10.1016/S0278-6915(03)00165-0

Jou LJ, Liao CM (2006) A dynamic artificial clam (Corbicula fluminea) allows parsimony on-line measurement of waterborne metals. Environ Pollut 144:172-183. doi:10.1016/j.envpol. 2005.12.032

Lamm SH, Engel A, Penn CA, Chen R, Feinleib M (2006) Arsenic cancer risk confounder in southwest Taiwan data set. Environ Health Perspect 114:1077-1082

Liao CM, Chen BC, Singh S, Lin MC, Han BC (2003) Acute toxicity and bioaccumulation of arsenic in tilapia Oreochromis mossambicus from blackfoot disease area in Taiwan. Environ Toxicol 18:252-259. doi:10.1002/tox.10122

Liao CM, Jou LJ, Chen BC (2005) Risk-based approach to appraise valve closure in the clam Corbicula fluminea in response to waterborne metals. Environ Pollut 135:41-52. doi:10.1016/ j.envpol.2004.10.015

Lin MC, Liao CM, Liu CW, Singh S (2001) Bioaccumulation of arsenic in aquacultural large-scale mullet Liza macrolepis from blackfoot disease area in Taiwan. Bull Environ Contam Toxicol 67:91-97

Lin MC, Lin HY, Cheng HH, Chen YC, Liao CM, Shao KT (2005) Risk assessment of arsenic exposure from consumption of cultured milkfish, Chanos chanos (Forsskål), from the arsenic-contaminated area in southwestern Taiwan. Bull Environ Contam Toxicol 75:637-644. doi:10.1007/s00128-0050800-2

Liu CW, Liang CP, Huang FM, Hsueh YM (2006) Assessing the human health risks from exposure of inorganic arsenic through oyster (Crassostrea gigas) consumption in Taiwan. Sci Total Environ 361:57-66. doi:10.1016/j.scitotenv.2005.06.005

Liu CW, Liang CP, Lin KH, Jang CS, Wang SW, Huang YK et al (2007) Bioaccumulation of arsenic compounds in aquacultural clams (Meretrix lusoria) and assessment of potential carcinogenic risk to human health by ingestion. Chemosphere 69:128134. doi:10.1016/j.chemosphere.2007.04.038

Newton TJ, Cope WG (2007) Biomarker responses of unionid mussels to environmental contaminants. In: Farris JL, van Hassel 
JH (eds) Freshwater bivalve ecotoxicology. Roca Raton, London, pp 257-284

Ortmann C, Grieshaber MK (2003) Energy metabolism and valve closure behaviour in the Asian clam Corbicula fluminea. J Exp Biol 206:4167-4178. doi:10.1242/jeb.00656

Sluyts H, van Hoof F, Cornet A, Paulussen J (1996) A dynamic new alarm system for use in biological early warning system. Environ Toxicol Chem 15:1317-1323. doi:10.1897/1551-5028(1996)015 $<$ 1317:ADNASF $>2.3 . \mathrm{CO} ; 2$

Tran D, Ciret P, Ciutat A, Durrieu G, Massabuau JC (2003) Estimation of potential and limits of bivalve closure response to detect contaminants: application to cadmium. Environ Toxicol Chem 22:914-920. doi:10.1897/1551-5028(2003)022<0914: EOPALO $>2.0 . \mathrm{CO} ; 2$
Tran D, Fournier E, Durrieu G, Massabuau JC (2004) Copper detection in the freshwater clam Corbicula fluminea: optimum valve closure response. Aquat Toxicol 66:333-343. doi:10.1016/ j.aquatox.2004.01.006

Tran D, Fournier E, Durrieu G, Massabuau JC (2007) Inorganic mercury detection by valve closure response in the freshwater clam Corbicula fluminea: integration of time and water metal concentration changes. Environ Toxicol Chem 26:1545-1551. doi:10.1897/06-390R1.1

van der Schalie WH, Sheld TR, Knechtges PL, Widder MW (2001) Using higher organisms in biological early warning systems for real-time toxicity detection. Biosens Bioelectron 16:457-465. doi:10.1016/S0956-5663(01)00160-9 